$$
\text { "szinger" — 2008/9/1 — 18:32 — page } 153 \text { — \#1 }
$$

\title{
The development of geometrical concepts in lower primary Mathematics teaching
}

\section{The square and the rectangle}

\author{
Ibolya SZILÁGyiné SZINGER
}

\begin{abstract}
Our research question is how lower primary geometry teaching in Hungary, particularly the concept of squares and rectangles is related to the levels formulated by van Hiele. Moreover to what extent are the concrete activities carried out at these levels effective in evolving the concepts of squares and rectangles.

In the lower primary geometry teaching (classes 1-4) the first two stages of the van Hiele levels can be put into practice. By the completion of lower primary classes level 3 cannot be reached. Although in this age the classes of concepts (rectangles, squares) are evolved, but there is not particular relationship between them. The relation of involvement is not really perceived by the children.
\end{abstract}

Key words and phrases: mathematics teaching, square, rectangle.

ZDM Subject Classification: A02, C72, G02, G42.

\section{Introduction}

In Hungary during the first four years of geometry teaching the basis is laid down and the aim in the initial stage of primary school is to develop the abilities of learners for being able to gain knowledge on their own.

The basis of learning geometry lies in inductive cognition gained from experience. Starting out from the concrete, gathering experience from various activities can lead to the formulation of general relationships. In the frame curriculum the development of orientation in plane and space, the approach to geometry through 


$$
\text { "szinger" — 2008/9/1 — 18:32 — page } 154 \text { — \#2 }
$$

geometrical shapes, recognition of formal and quantitative properties and simple transformation are particularly highlighted.

In the lower primary the basics of mathematical concepts are laid down. In this paper the development of the concepts of squares and rectangles and their relationship to each other is examined. In the framework curriculum the teaching material related to squares and rectangles is as follows:

Grade 1: Presenting plane figures through activities. Sorting out plane figures, according to their properties. Some of the observed attributes of figures. Recognition of geometric properties, comparisons.

Grade 2: Copying and presenting plane figures according to one or two conditions. Gaining experience in simple shapes, the formulation of observations. Some properties of polygons. Producing rectangles and squares.

Grade 3: Producing plane figures without restrictions, by copying and with one or two restrictions. Producing axial symmetric figures through activities. The properties of rectangles and squares: the number of sides and vertexes, size. Comparison. Measuring angles by incidental units in practice.

Grade 4: Producing plane figures according to given restrictions Stretching parallel and perpendicular pairs of lines on nailed board. Measuring angles by right angle, its half and its quarter.

In the framework curriculum the hierarchical relationship between squares and rectangles is not mentioned and also problems may arise from the fact that the definitions of squares in course books for fourth grade pupils are as follows: "Squares are rectangles whose every side is of the same length" (C. Neményi, 2005). "Squares are rectangles whose every side is equal" (Török, 2002; Hajdu, 2005).

In the frame curriculum the proper use of mother tongue and technical terminology is emphasized. Thus, the question is to what extent these definitions are suitable for the characteristics of the learners' age group. Do they actually consider squares as rectangles, or not, i.e. are they totally different concepts for them? We also intend to find an answer to this question.

The evolvement of some geometrical concepts, such as squares and rectangles have been examined in an educational development experiment conducted with fourth class pupils. 


$$
\text { "szinger" — 2008/9/1 — 18:32 — page } 155 \text { — \#3 }
$$

\section{Theoretical background}

It is already in the kindergarten where the guided process of acquiring knowledge in geometry begins. The process of evolving geometrical concepts (geometric solids, plane figures) starts as children are examining the shapes of the objects in their environment. It is a higher stage of acquiring knowledge that the characteristics of these sets of objects are recognized. In the references the process of acquiring knowledge in geometry is widely treated, but in this experiment we have relied on the views of P-H. van Hiele. According to P-H. van Hiele, the process of acquiring knowledge in geometry can be divided into five stages.

(Level 1) At the level of global recognition of shapes children perceive geometrical shapes as integral whole. Children easily recognize various shapes according to their forms, they also learn the names of shapes however, and they do not see the connection between the shapes and their parts. They do not recognize the rectangular prism in a cube, the rectangle in the square, because these seem to be totally different for them.

(Level 2) At the level of analyzing shapes, children break down the shapes into parts, and then they put them together. They also recognize the planes, edges and the vertexes of geometrical forms, and the plane figures of geometric shapes which are delineated by curves, sections, and dots. At this level a great importance is attached to observation, measuring, folding, sticking, modeling, laying parquet, using mirrors etc. By means of these activities children can recognize and list the properties of the shapes (parallel planes or sides, perpendicular, the properties of symmetry, right angles, etc), but they do not come up with definition and they do not see the logical relationship between the properties. Even if children perceive what squares and rectangles have in common, it cannot be expected that they could draw the conclusion that squares are actually rectangles. At this level children are not able to notice the relationships between shapes.

(Level 3) At the level of local logical arrangement learners can see the relationships between the properties of a given shape or between various shapes. They can also come to a conclusion from one property of shapes to another. They also realize the importance of definition. The course of logical conclusions is however determined by the textbook and the teacher actually. The demand for verification is being started, although it applies only for shapes. At this level the squares are considered as rectangles.

Level 4 (aiming at a complete logical setup) and level 5 (axiomatic setup) are to be reached in secondary and tertiary education. 
In the van Hiele model the cognition of each stage of learning is based on and enhanced on the previous stage. The transition from one stage to the other happens continually and gradually and during this time the mathematical concepts of each stage are acquired. This process is particularly influenced by the content and the method of teaching. None of the stages can be skipped in order to establish proper geometrical thinking. Every stage has its own terminology, system of signs and logical structure. According to van Hiele it cannot be expected from learners at a lower stage to be able to understand the instructions of a higher stage. He thinks that one of the main causes of failures in mathematics teaching is that it still frequently happens.

While evolving a mathematical concept, it has to be fitted into the system of already established concepts (assimilation), but it also happens that the established system or pattern has to be modified in order to fit the new concept (accommodation). The balance of assimilation and accommodation is indispensable to the proper evolvement of concepts. If this does not happen i.e. assimilation is not followed by proper accommodation, the learner's own individual explanations will find their way into the knowledge of mathematics, which later may cause a disorder in concepts. The definitions of concepts created in this way can be uncertain and inaccurate.

Teaching geometrical concepts takes a long time. The principle of progression and exact definitions are essential but not by all means. Sometimes even in lower primary classes definitions are provided in textbooks as well, when actually there is not enough experience and the required level of abstraction. As the mathematician-psychologist R. Skemp says:

"By means of definition we cannot pass on concepts of higher order than he already knows only if we provide a large amount of proper examples. As in mathematics the examples mentioned above are almost all of them various concepts, we first of all have to check whether the learners have already acquired these concepts or not... The selection of suitable examples is not as easy as it looks. All the common properties must be found in the examples that make up the concept, but the examples must not have any other shared properties." (Skemp, 1975) 


$$
\text { "szinger" — 2008/9/1 - 18:32 — page } 157 \text { - \#5 }
$$

\section{Research question}

The research question is how lower primary geometry teaching in Hungary, particularly the concept of squares and rectangles is related to the levels formulated by Hiele. Moreover to what extent are the concrete activities carried out at these levels effective in evolving the concepts of squares and rectangles.

\section{Hypothesis}

In the lower primary geometry teaching (classes 1-4) the first two stages of the van Hiele levels can be put into practice. By the completion of lower primary classes level 3 cannot be reached. Although the classes of concepts (rectangles, squares) are evolved, but there is not particular relationship between them. The relation of involvement is not really perceived by the children.

\section{Research background}

The developmental teaching experiment was conducted in 2006 May and June. The content and the method of the classes were carried out by the author, who also took part in the lessons. The teacher was a mathematics teacher in the 4.c class of the Practice School of József Eötvös College in Baja, whose job was assisted by the author in presenting, modeling, raising supplementary questions or alternative explanations. Both of them helped the pupils in carrying out and solving the tasks in individual or pair work. Both checking and evaluation were done in cooperation. During the developmental teaching the evolvement of several geometrical concepts such as squares, rectangles, parallel, perpendicular, symmetry was examined but here we are going to focus on the formation of the concepts of squares and rectangles.

The developmental teaching experiment included 16 lessons and the aim was to put the van Hiele model of geometry teaching into practice. In the first lesson a pre-test was done by 26 pupils of class 4 so that we could see that the transition from level 1 (the global recognition of shapes) to level 2 (the analysis of shapes) and the further development of geometric thinking is possible. When compiling the pre-test, the syllabus of class 3 and the comments of the mathematics teacher were taken into consideration. The first lesson of the developmental teaching experiment was as a matter of fact the first lesson of the geometry topic as well. 
In a conversation the form-master introduced the children, their family and social background and their aptitude level. Six of them were excellent, 12 of them good, five of them satisfactory, and three of them had poor results.

All the facilities and equipment were provided by the practice school.

\section{The tasks and evaluation of the pre-test}

The first two tasks of the pre-test are meant to present the conceptual level of squares and rectangles. The first task involves the creation of the concepts of quadrangles, rectangles, squares, and the second task is about identifying (recognizing) concepts.

In the first task pupils were asked to draw a quadrangle (a), rectangle (b), a square $(\mathrm{c})$.

The results are shown in the table below.

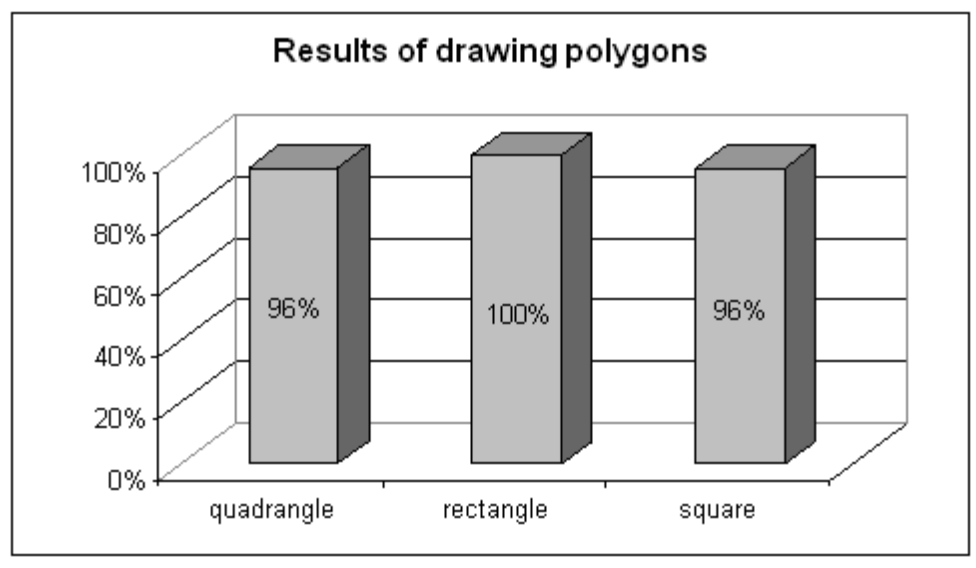

Children were good at solving the task, actually only one of them was not able to draw quadrangle and another one was not able to draw a square. A relatively large number of pupils $(42 \%)$ drew a square as a quadrangle as well. They probably could not make a difference between these two concepts. 


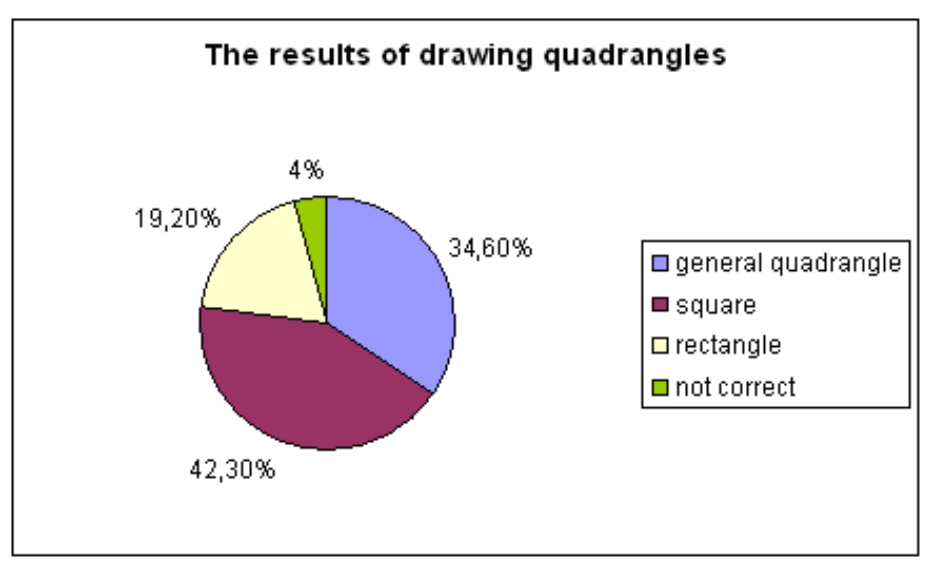

In the second task pupils had to select out of 16 plane figures the ones which meet the conditions below:

a) the ones delineated by straight lines

b) quadrangles

c) rectangles

d) squares

The plane figures that learners selected from:

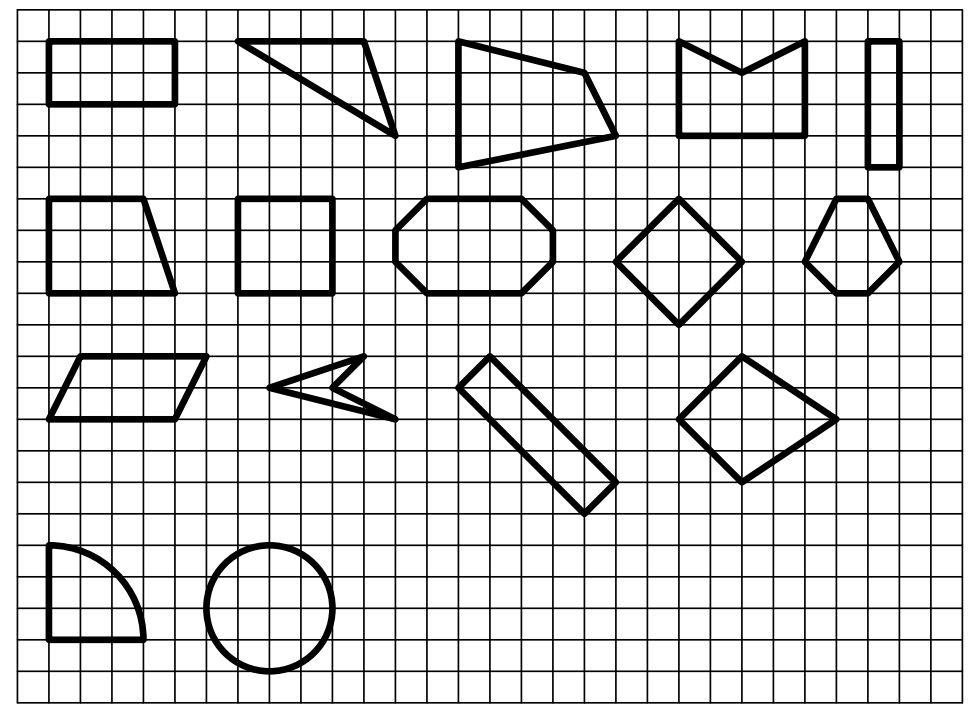


The evaluation of task 2

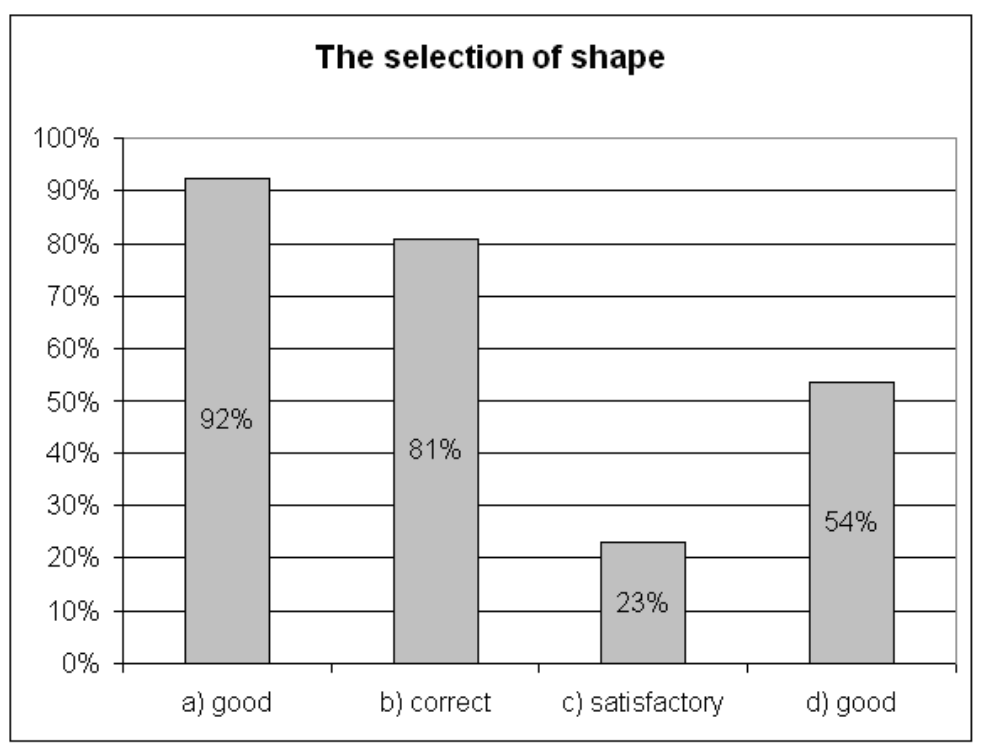

As it is shown by the data, more development of the concepts is required in case of rectangles and squares. In task c) satisfactory solutions were seen the ones, in which squares were not considered as rectangles. But there were no other mistakes. Since we do not expect children at this age to be able to realize that squares are rectangles. Which is why we have accepted thse as satisfactory solutions. Almost $20 \%$ of the pupils did not consider squares as rectangles, but they did not make any other mistake. Almost $70 \%$ of them did not consider squares as rectangles, but the general parallelograms. Almost $90 \%$ of the children did not consider squares as rectangles. This is completely in line with Hiele's first two levels. It is also worth mentioning that $27 \%$ of the children did not recognize the square turned on its vertex. The number of mistakes indicates that further on for the proper formation of concepts more attention should be paid to the presentation and discussion of proper examples and counter examples? By proper examples I mean the right amount of examples and counter examples on the one hand and their variety on the other. (E.g. the learners should see rectangles and squares in various positions.) Moreover the essential characteristics pertaining to the concept should be recognizable, and the unimportant ones should be noticeable for the children. 


$$
\text { "szinger" — 2008/9/1 — 18:32 — page } 161 \text { — \#9 }
$$

Comparing the results of the two tasks it can be seen that in task 1 drawing given concepts was a lot more successful than their recognition in task 2 . The irrelevant characteristics of a concept are called noise by Skemp. In task 2 the level of noise was increased, the problem became more complicated and the essential characteristics got blurred for the children. The poor results were due to this fact and it also indicates that neither the concept of rectangle nor that of the square is firmly established. The concepts are clear and definite when they can be selected even in a big noise.

\section{The teaching experiment}

The content of the developmental teaching experiment was designed among others on the basis of the pre-test results. The development of the concepts of quadrangle, rectangle and square is justified by the fact that most children think of special cases, (squares and rectangles) in case of quadrangles. And $70 \%$ of them considered the general parallelograms as rectangles. As many as one third of them did not recognize squares turned on its point vertex.

When compiling the teaching material the level of noise was continuously increased. During the first lessons we dealt with rectangles and squares as the faces of rectangular prisms and cubes. By examining the opposite and neighboring planes the new concept of 'parallel' and 'perpendicular' were introduced and after spreading the solids we turned to plane figures.

The detailed description of the lessons can be found below:

Lesson 1: Pre-test.

Lesson 2: Naming and describing rectangular objects, such as matchboxes, cupboards etc, the number of vertexes, edges and sides, comparing the length of edges, the shape and the size of the sides, understanding what opposite and neighboring sides are and their position. Naming and describing cubic objects: the number of vertexes, edges and sides, comparing the length of the edges, the shape and size of sides, understanding what opposite and neighboring sides are and their position.

Lesson 3: Giving a list of the characteristics of rectangular prisms and cubes by means of models. Making up various rectangular prisms using four matchboxes. Producing the reflections of the solid made from matchboxes. Finding objects in symmetrical arrangement in the classroom. Listing symmetrical 


$$
\text { "szinger" — 2008/9/1 — 18:32 — page } 162 \text { — \#10 }
$$

objects. Defining the position of the planes of symmetry in case of various solids.

Lesson 4: Defining the position of the planes of symmetry in rectangular prisms and cubes. By using a model, learners studied the parallel and perpendicular position of the opposite and the neighboring sides of rectangular solids, regular pentagon prisms, quadrilateral pyramids. Spreading rectangular prisms and cubes, examining the shape and size of the sides. Cutting squares from rectangles.

Lesson 5: The various grids of cubes. Studying the rectangles. The number of vertexes, opposite and neighboring vertexes, diagonal. Cutting the rectangle into two along the diagonal. Producing other plane figures by fitting the triangles gained in this way, and naming them. Gathering experience on plane figures and describing them. Further study of the rectangles: the number of sides, comparison of their length, determining the opposite and neighboring sides, the parallel position of the opposite sides, the perpendicular position of the neighboring sides. Measuring the sizes of angles by means of folded right angles.

Lesson 6: Studying the characteristics of plane figures made from two congruent right-angled triangles during the previous lesson: the number of vertexes and sides, defining the opposite and neighboring vertexes and sides, comparing the length of the sides, studying the parallel and perpendicular position of the opposite and the neighboring sides, the size of the angles. Comparing the characteristics of rectangles and parallelograms and highlighting their differences. Studying squares: the number of vertexes, opposite and neighboring vertexes, the diagonal. Cutting the square into two parts along the diagonal. Producing plane figures from the two right-angled isosceles triangles. Further study of squares: the number of sides, comparing their length, opposite and neighboring sides, the parallel and perpendicular position of the opposite and neighboring sides, the size of the angles.

Lesson 7: Demonstrating parallel and perpendicular pairs of straight lines as well as straight lines which are not parallel and perpendicular. Producing plane figures cut out from paper without restriction, and describing their characteristics. Listing the characteristics of rectangles and squares. Producing planes figures from the 2, 3, 4 and 6 regular triangles from the set of logics, which consists of 48 various plane figures, which can be red, yellow, blue or green. Their sizes are, small or large, their shape can be circle, square 


$$
\text { "szinger" — 2008/9/1 — 18:32 — page } 163 \text { — \#11 }
$$

or triangle, their surface can be smooth or there is a hole in them. Making observations on parallel pairs of sides. Producing rectangles of different length and identical height from strips of paper.

Lesson 8: Producing various plane figures from paper strips by one cut. Naming them and describing their characteristics and shared characteristics. Cutting general rhombus from rectangle, its characteristics. Cutting general deltoid from rectangle, and its characteristics. Making rectangles and then the "frame" of a general parallelogram from six match sticks. Making squares then general rhombus from four match sticks. Comparing the characteristics of squares and rhombuses.

Lesson 9: Comparing the characteristics of squares and rectangles. Making 2 rectangles, a pentagon and a triangle, a triangle and a quadrangle, 2 quadrangles and 2 triangles from a rectangle by one cut. Drawing squares on square grid.

Lesson 10: Drawing various quadrangles on square grid. Drawing various triangles on grid. Drawing parallel and perpendicular pairs of straight lines.

Lesson 11: Coloring the parallel pairs of sides of the quadrangles drawn on grid and designating the right angles. In triangles coloring the sides perpendicular to each other. Drawing quadrangles according to given requirements. Studying the structure of the edges of rectangular prism and cubes. Observing the parallel and perpendicular edges.

Lesson 12: Producing reflection on plane through activity: folding a painted sheet of paper, on a black photographic paper folded into two making a pattern by running a pin through it, then unfolding it holding it in the direction of light. Cutting a given pattern from a sheet of paper folded into two parts. Observing reflections. On grid reflecting given figures on given axis. Producing figures symmetrical on axis by clipping.

Lesson 13: Finding the symmetry axes of plane figures cut out from paper by means of folding and mirror. Formulating experiences and observations. Drawing plane figures which have no symmetry axis, and which have exactly $1,2,3$ and 4 symmetry axes.

Lesson 14: Producing figures symmetrical on axis on square grid. Selecting plane figures according to given characteristics. Formulating statements "every" and "there is such ..." 
Lesson 15: Selecting plane figures according to given characteristics. Establishing the logical validity of statements. Drawing plane figures according to given requirements. Twenty questions.

Lesson 16: Post test.

In the lesson plans what we aimed at was that children could be able to sort of discover the geometrical concepts first on the basis of concrete experience in real games and activities then visually (drawing) and finally at an abstract level.

\subsection{Activities}

a) What is the simplest way of cutting squares from rectangles?

b) Rectangles and squares are cut at the diagonal into two triangles and then creating new planes figures.

c) Using paper strips to produce and name various planes figures by one straight cut.

d) Producing rectangles of various lengths but of a given height.

e) Making the 'frame' of a rectangle, and a general paralelogramme from six matches.

f) Making the 'frame' of a square and later a general rhombus from four matches. Etc.

The minutes of the lessons are available. E.g. in task D a little boy called Bence was desperate when he said:

'In one of them all sides are equal. I measured and all sides are $4 \mathrm{~cm}$ long, this is a square. It is not correct.'

The teacher said:

'You managed like this. What you have is a special rectangle, you see, the square is a special rectangle. Your solution is OK.'

And Bence relieved with a big sigh. The teacher showed Bence's rectangle to the class and as it turned out, it was not only him who managed to cut a rectangle like this, and what the teacher said to Bence was also repeated to the whole class. We were happy to have a chance to highlight the 'relationship' between the square and the rectangle.

Presenting task e) we intended to point out the difference between the characteristics of rectangles and general paralellogrammes. Children realized that whereas the neighbouring sides of the rectangle are perpendicular and the sides 


$$
\text { "szinger" — 2008/9/1 — 18:32 — page } 165 \text { — \#13 }
$$

of the paralellogramme are 'slanted'. The size of the angles were checked by using folded right angle, and they could see that none of the angles were right angles.

\subsection{Visual tasks}

a) drawing squares and rectangles on square grid

b) drawing various quadrangles on square grid

c) drawing various triangles on square grid

d) drawing pairs of parallel and perpendicular straight lines

e) colouring the parallel side pairs of various plane figures and marking right angles

f) drawing quadrangles of given characteristics

Etc.

When drawing quadrangles (b) it was necessary to explain the meaning of the word 'various'. Thus they realized that two quadrangles are different when we cut them out and place them on each other and they do not fit. Children had seven minutes to do the task. Out of the 16 solutions ten was found by four children, and there were no better solutions.

In task e) when coloring the parallel sides of a general trapezoid the following conversation took place between David and the author:

'You colored nothing in this quadrangle. Didn't you find parallel straight lines?'

At this point, the teacher placed the sticks on the two bases and David could see that they did not meet. David commented like this:

'It is true that the sticks do not meet, but the sides are not of equal length, thus they cannot be parallel.'

The author referring to the antecedents said:

'This was not a precondition in case of parallels.'

Then David said:

'Oh, yes, they are parallel'.

Then he corrected the mistakes.

In a task related to polygons Kornél raised the following question:

'Are polygons which have two angles?'

The teacher asked.

'Can you draw anything like that?'

'Yes, I can', said Kornél and he drew a semi-circle. 
Looking at the drawing the teacher asked:

'Are polygons delineated by curves?'

Kornél thought about it for a while and responded:

'Not really, only by straight lines. Then this is not a polygon.'

\subsection{Abstract level}

After gaining experience at the previous two levels, the summary of the properties of the various geometrical shapes took place at an abstract level. In case of some polygons, particularly squares and rectangles, counting the number of sides and points repeatedly, examining the length, the parallel and perpendicular position of the sides, determining the number of symmetry axes and the size of the angles produced by neighboring sides. The properties of squares and rectangles were also compared. To the question raised by the teacher, whether all the properties of the rectangle are valid for the square, most pupils responded by saying no. Only two pupils believed it was true. The teacher tried to persuade the children, but some of them told the supervisor that she was not really right, because 'the rectangles have two sides of different length, whereas the squares do not.' Obviously the examination of geometrical properties was accompanied by the visual representation of the given shapes.

Children like playing twenty questions, and the game is also suitable for practicing and memorizing the properties of plane figures. When they tried to guess if it was the rectangle they had to find out, the questions raised by the pupils were as follows:

Does it have five points? Is it a quadrangle? Does it have a right angle? Are the opposite sides parallel? Does it have a symmetry axis? Are the sides of the same length? Does it have perpendicular sides? (The teacher said they could have found out based on a previous question). Does it have several right angles? Does it have four right angles? Finally they found out what it was.

\section{The tasks of the post-test and its evaluation}

The development experiment was completed by a survey. The test was done by 25 pupils in class 4/c. In class 4/a 23 pupils and in class 4/b 24 pupils did the same test respectively. In these classes there were two math teachers. 
In the test only the tasks related to the formation of concepts of squares and rectangles were evaluated. In the task of identifying the concepts of quadrangles, rectangles and squares out of fifteen plane figures
a) the quadrangles,
b) the rectangles,
c) the squares had to be selected.

This set had to be arranged:

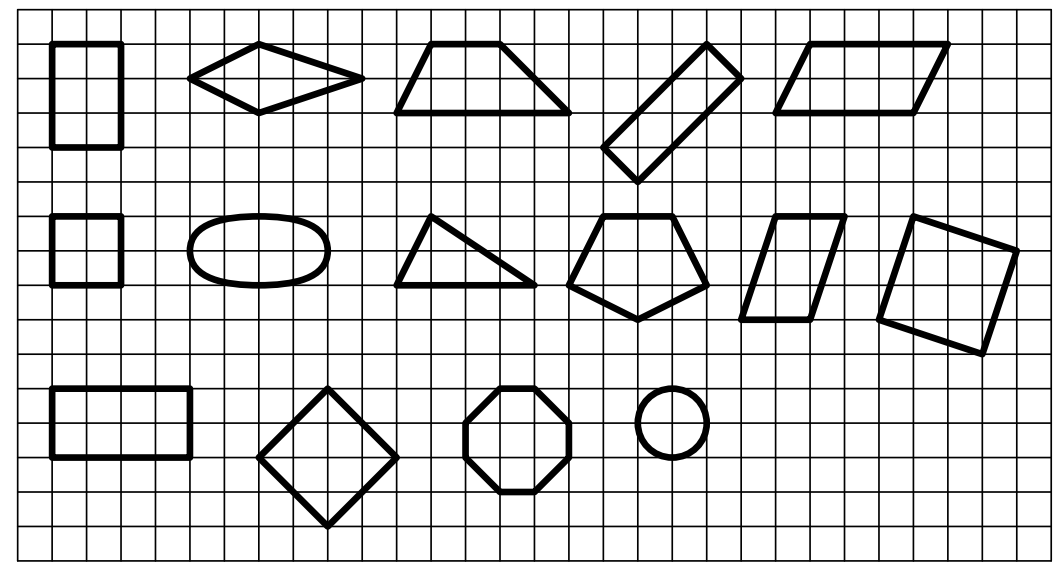

The results of solving the tasks are shown in the chart below.

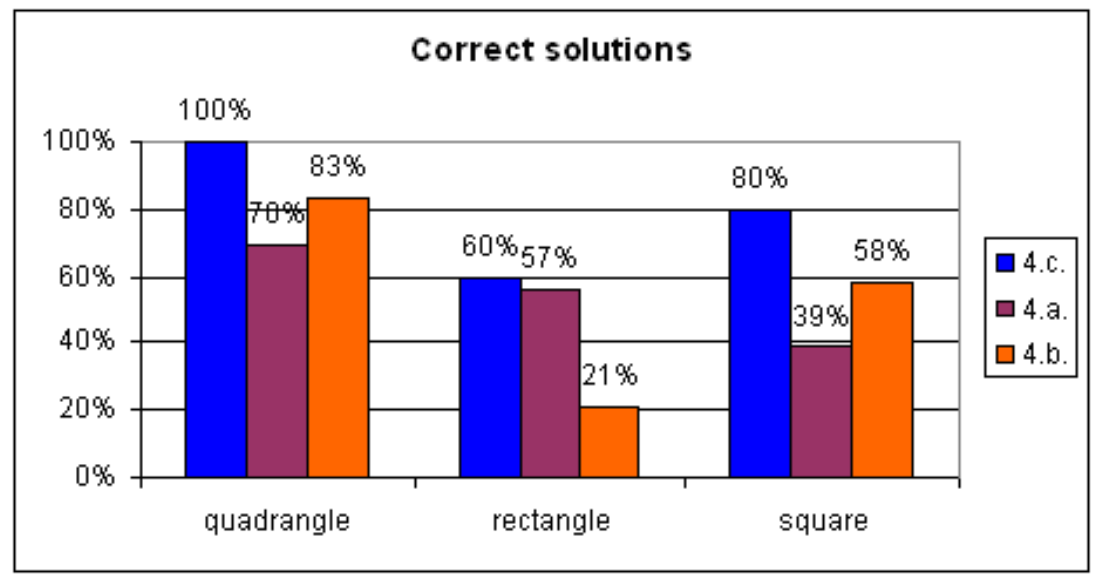


The recognition of quadrangles in the class of the experiment was absolutely correct. In the selection of rectangles the ones were also considered as correct, where squares were not seen as rectangles. (As this happened in case of the pretest.) $52 \%$ of the pupils did not rank squares among the rectangles, but there was no other mistake. Comparing to the $20 \%$ of the pre-test the improvement is quite significant. $40 \%$ of the children did not rank squares among rectangles, but they did so with the general parallelograms. This is quite an improvement compared with the $70 \%$ in the previous test. Invariably $90 \%$ of the children do not consider squares as rectangles. The proportion is almost the same in the control group. These data support the hypothesis that it is not possible to reach Hiele's level 3 by the completion of the lower primary classes. What is only realistic is the completion of the two levels.

There was also a positive change in the recognition of squares. In comparison with the previous $54 \%$, the squares were correctly ranked by $80 \%$ of the children.

In the worksheet of the survey on squares and rectangles children were asked to underline the statements that were true for

a) squares

Its opposite sides are parallel.

Its opposite sides are perpendicular.

The neighboring sides are parallel.

The neighboring sides are perpendicular.

Every angle is right angle.

Not every angle is right angles.

It has exactly two symmetry axes.

It has four symmetry axes.

It has 8 symmetry axes.

Its every side has same length.

Its opposite sides have same length.

b) rectangles

Its opposite sides are parallel.

Its opposite sides are perpendicular.

Its neighboring sides are parallel.

Its neighboring sides are perpendicular.

Its angles are all right angles.

Its angles are not all right angles.

It has four symmetry axes.

It has four symmetry axes. 
The diagonals are symmetry axes.

Every side has same length.

The opposite sides have same length.

In the evaluation of the tasks we have focused on only the results without any mistake. In the experimental group all the true statements related to the properties of the square were chosen by 52 of the pupils, whereas in the control group the results were $35 \%$ and $42 \%$. In case of rectangle the results were as follows: In the experimental group it was $64 \%$ in the control groups $39 \%$ and $70 \%$. The mistakes can be due to the misunderstanding of the terms 'opposite' and 'neighboring' on the one hand and in the fact the concepts of parallel and perpendicular were not firmly established.

In the last task of the survey the hypothesis was also supported. In this task the logical validity of the following statements had to be decided:

a) Rectangles are special squares.

b) Squares are special rectangles.

c) The sides of the squares are not equal.

d) All squares are rectangles as well.

The results are shown below:

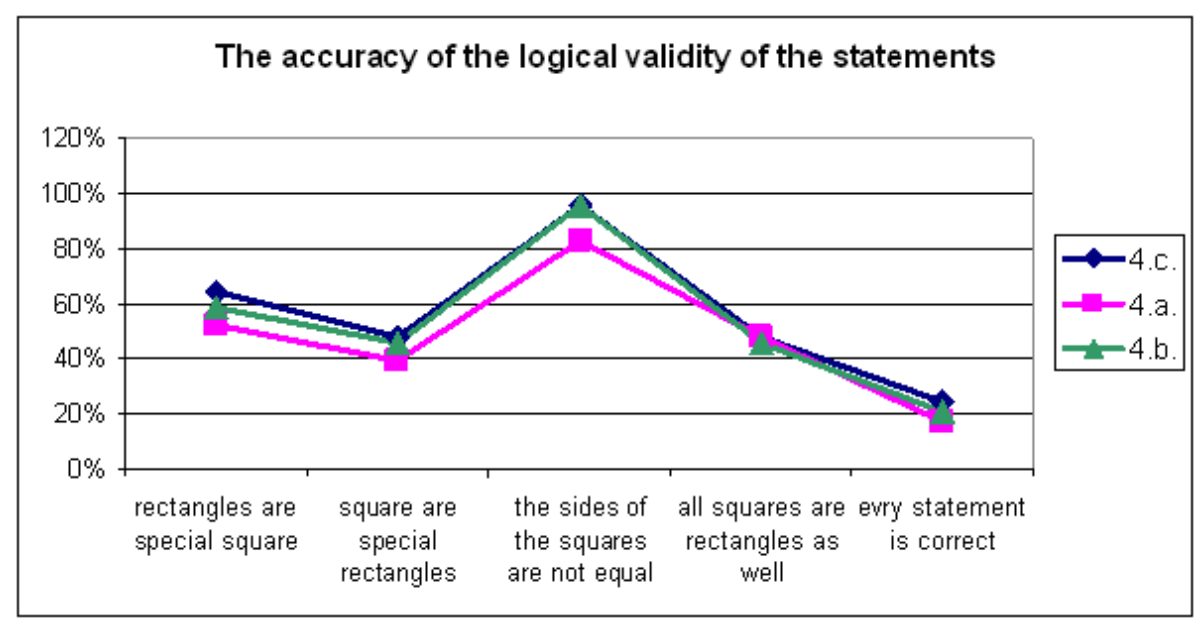

In this task the number of accurate solutions is rather low; this is no wonder, as three of the four statements related to the hierarchy between squares and rectangles. And we cannot be absolutely certain about the fact that the children who thought that both statement one and statement four are true are really aware 
of the sub-set relationship between squares and rectangles. Those who considered these statements of different logical validity (in the experimental group $40 \%$ of the learners and in the control groups $43 \%$ and $46 \%$ of the learners) came to contradictory conclusions, which show that the relationship between concepts of squares and rectangles is rather uncertain. Those who considered both of them false $(32 \%, 34 \%$ and $35 \%$ of the learners) could not really see any hierarchy.

\section{Conclusion}

The developmental project guided by the author efficiently contributed to a better understanding of the concept of rectangles and squares. This fact is also supported by the results of the pre-test and the final worksheet. The efficiency is also shown by the fact that the achievement in the experimental group was better, occasionally much better than in the two other control groups, as it can be seen in the graph. As the above samples are not representative, no statistical trials have been carried out.

The answer to the question raised in the introduction, namely whether four grade pupils consider squares as rectangles, according to the results of the experiment is the following. Most of them do not consider squares as rectangles, as they are able to reach van Hiele's level 2 at most.

The cognition of learners at the age of 6-10 is strongly attached to real life, which is why the formation of concepts should be based on concrete, manual activities and examples taken from their immediate surrounding, which can lead to the formation of abstract concepts. In order that children recognize the essential characteristics of a concept and reach abstract thinking, several examples, counter examples making the concept tangible, modeling are essential preconditions.

As György Pólya said: "We should not pass up, anything that could bring mathematics closer to students. Mathematics is a very abstract science and this is why it has to be presented in a very concrete way."

\section{References}

[1] Ambrus András, Bevezetés a matematikadidaktikába, ELTE Eötvös Kiadó, 1995 (in Hungarian).

[2] C. Neményi Eszter, Káldi Éva, Matematika tankönyv általános iskola 4. osztály, Nemzeti Tankönykiadó, Budapest, 2005, p. 125 (in Hungarian). 


$$
\text { "szinger" — 2008/9/1 — 18:32 — page } 171 \text { — \#19 }
$$

[3] Falus Iván (ed.), Bevezetés a pedagógiai kutatás módszereibe, Műszaki Könykiadó, Budapest, 2000 (in Hungarian).

[4] Majoros Mária, Oktassunk vagy buktassunk?, Calibra Kiadó, Budapest, 1992 (in Hungarian).

[5] Peller József, A matematikai ismeretszerzési folyamatról, ELTE Eötvös Kiadó, Budapest, 2003 (in Hungarian).

[6] Peller József, A matematikai ismeretszerzés gyökerei., ELTE Eötvös Kiadó, Budapest, 2003 (in Hungarian).

[7] A. M. Piskalo, Geometria az 1-4. osztályban, Tankönykiadó, Budapest, 1977 (in Hungarian).

[8] Pólya György, A gondolkodás iskolája, Accord Kiadó, Budapest, 2000, p. 197 (in Hungarian).

[9] Scherlein Márta, Czakó Anita, Hajdu Sándor, Novák Lászlóné, Matematika 4., Müszaki Könyvkiadó, Budapest, 2005, p. 100 (in Hungarian).

[10] Richard R. Skemp, A matematikatanulás pszichológiája, Gondolat Kiadó, Budapest, 1975, pp. 38-39 (in Hungarian).

[11] Anne Teppo, Van Hiele Levels of Geometric Thought Revisited, Mathematics teacher (March 1991).

[12] Török Tamás, Matematika II. általános iskola 4. osztály, Nemzeti Tankönykiadó, Budapest, 2002, p. 36 (in Hungarian).

IBOLYA SZILÁGYINÉ SZINGER

H-6500 BAJA

BERECZKI MÁTÉ UTCA 19/A

HUNGARY

E-mail: Szilagyine.Szinger.Ibolya@ejf.hu

(Received December, 2007) 